\title{
Beginning jQuery
}

Jack Franklin 


\section{Beginning jQuery}

\section{Copyright $(2013$ by Jack Franklin}

This work is subject to copyright. All rights are reserved by the Publisher, whether the whole or part of the material is concerned, specifically the rights of translation, reprinting, reuse of illustrations, recitation, broadcasting, reproduction on microfilms or in any other physical way, and transmission or information storage and retrieval, electronic adaptation, computer software, or by similar or dissimilar methodology now known or hereafter developed. Exempted from this legal reservation are brief excerpts in connection with reviews or scholarly analysis or material supplied specifically for the purpose of being entered and executed on a computer system, for exclusive use by the purchaser of the work. Duplication of this publication or parts thereof is permitted only under the provisions of the Copyright Law of the Publisher's location, in its current version, and permission for use must always be obtained from Springer. Permissions for use may be obtained through RightsLink at the Copyright Clearance Center. Violations are liable to prosecution under the respective Copyright Law.

ISBN 978-1-4302-4932-0

\section{ISBN 978-1-4302-4933-7 (eBook)}

Trademarked names, logos, and images may appear in this book. Rather than use a trademark symbol with every occurrence of a trademarked name, logo, or image we use the names, logos, and images only in an editorial fashion and to the benefit of the trademark owner, with no intention of infringement of the trademark.

The use in this publication of trade names, trademarks, service marks, and similar terms, even if they are not identified as such, is not to be taken as an expression of opinion as to whether or not they are subject to proprietary rights.

While the advice and information in this book are believed to be true and accurate at the date of publication, neither the authors nor the editors nor the publisher can accept any legal responsibility for any errors or omissions that may be made. The publisher makes no warranty, express or implied, with respect to the material contained herein.

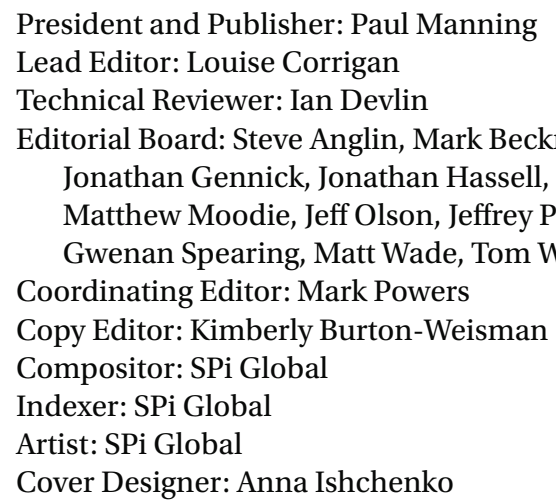

Distributed to the book trade worldwide by Springer Science+Business Media New York, 233 Spring Street, 6th Floor, New York, NY 10013. Phone 1-800-SPRINGER, fax (201) 348-4505, e-mail orders-ny@springer-sbm.com, or visit WwW. springeronline.com. Apress Media, LLC is a California LLC and the sole member (owner) is Springer Science + Business Media Finance Inc (SSBM Finance Inc). SSBM Finance Inc is a Delaware corporation.

For information on translations, please e-mail rights@apress.com, or visit www.apress.com.

Apress and friends of ED books may be purchased in bulk for academic, corporate, or promotional use. eBook versions and licenses are also available for most titles. For more information, reference our Special Bulk Sales-eBook Licensing web page at WwW. apress. com/bulk-sales.

Any source code or other supplementary materials referenced by the author in this text is available to readers at WWW. apress . com/9781430249320. For detailed information about how to locate your book's source code, go to WWW. apress.com/source-code/. 
Dedicated to Mum, Dad and Sam 


\section{Contents at a Glance}

Foreword xiii

About the Author XV

About the Technical Reviewer ....................................................................................... xvii

Acknowledgments xix

Chapter 1: JavaScript You Need to Know .................................................................. 1

Chapter 2: The Basics of jQuery …...................................................................................

Chapter 3: Traversing the DOM ............................................................................29

Chapter 4: DOM Manipulation with jQuery ...............................................................43

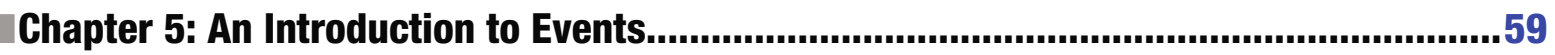

Chapter 6: More Events ....................................................................................... 71

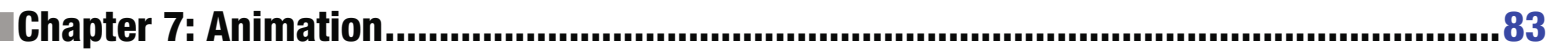

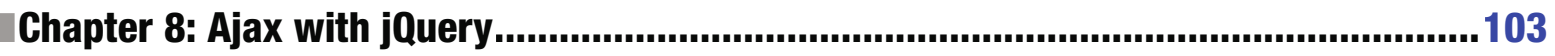

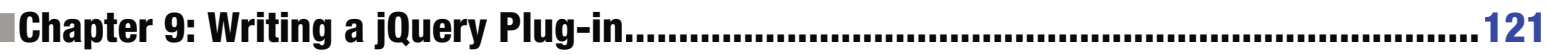

Chapter 10: More jQuery Plug-ins ..............................................................................139

Chapter 11: A jQuery Image Slider .........................................................................157

Index 


\section{Contents}

Foreword

About the Author xiii

About the Technical Reviewer XV

Acknowledgments xvii

Chapter 1: JavaScript You Need to Know 1

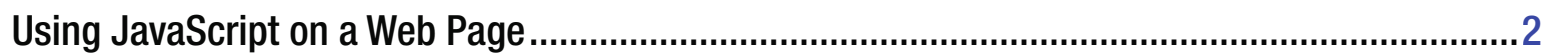

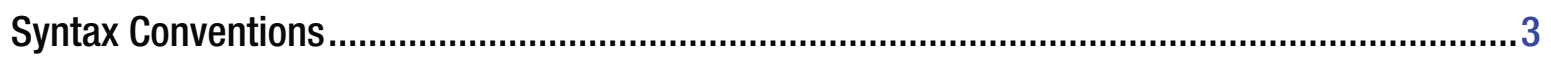

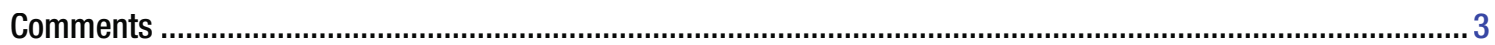

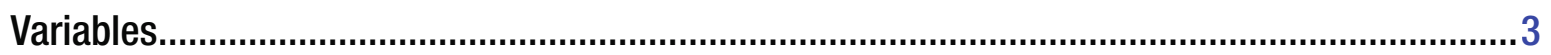

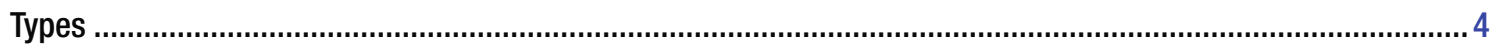

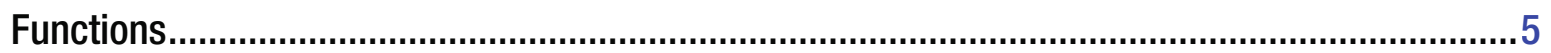

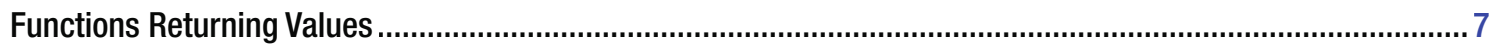

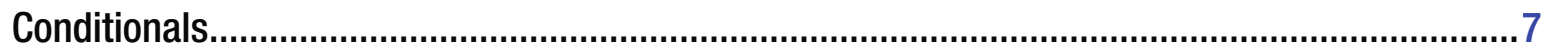

Debugging with the Console

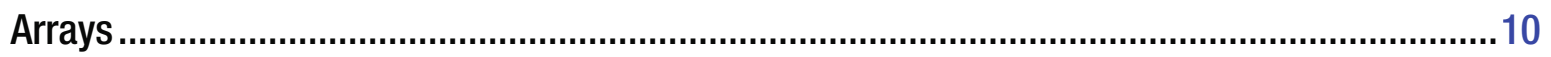

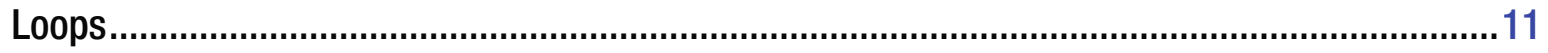

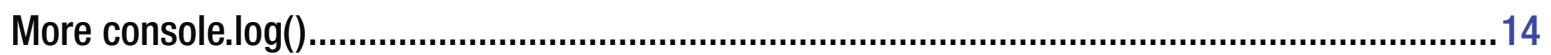

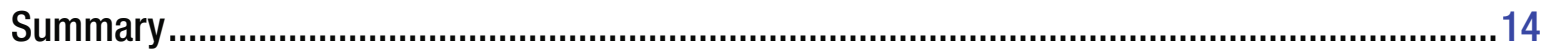

Chapter 2: The Basics of jQuery ............................................................................15

The Document Object Model (DOM) ……...........................................................................

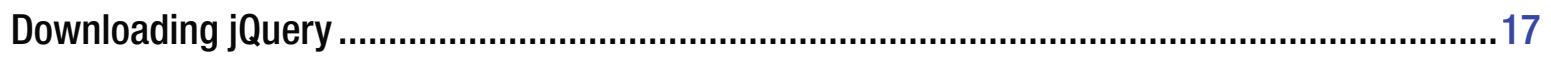

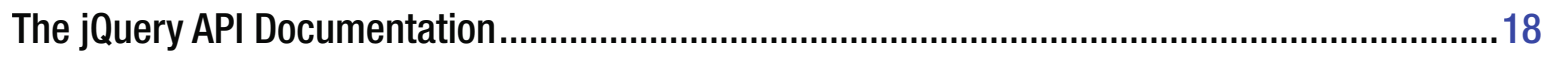


Writing Some jQuery

Animation Example

Summary.

Chapter 3: Traversing the DOM

CSS Selectors in jQuery.

Traversal Methods

Further Traversal

Chaining Methods

Further Filtering

Summary.

Chapter 4: DOM Manipulation with jQuery

CSS

animate() and Animation Convenience Methods

Attributes and Properties

text() and html()

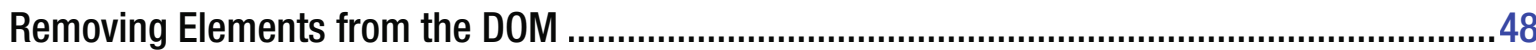

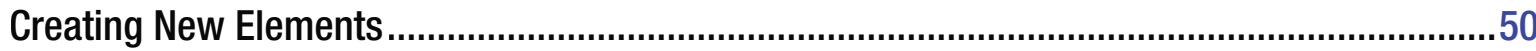

Inserting into the DOM

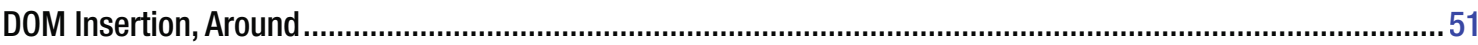

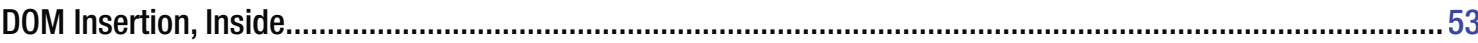

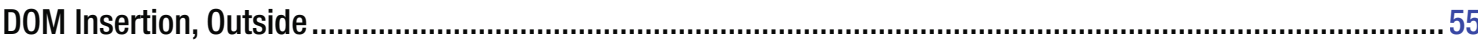

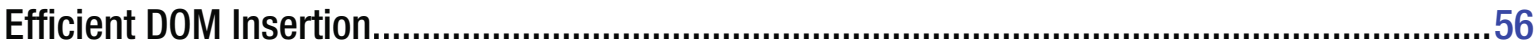

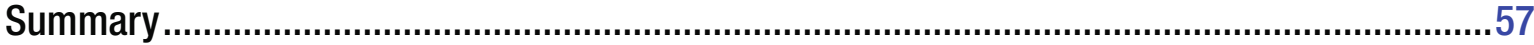

Chapter 5: An Introduction to Events.........................................................................59

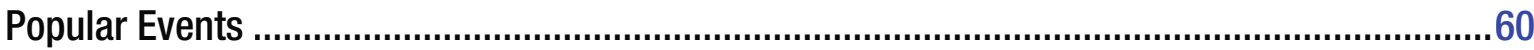

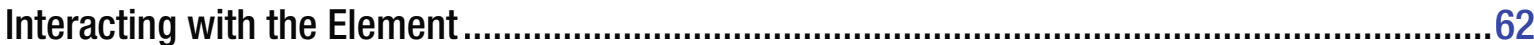

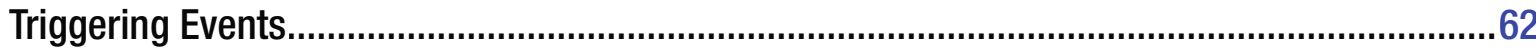

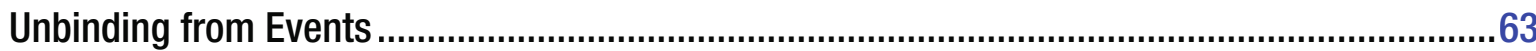

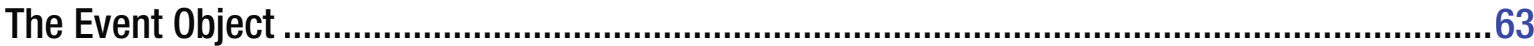




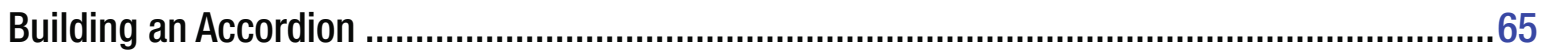

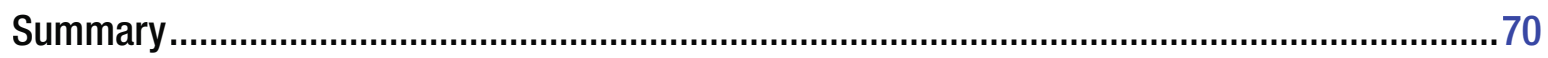

Chapter 6: More Events ........................................................................................... 71

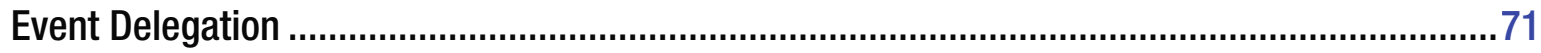

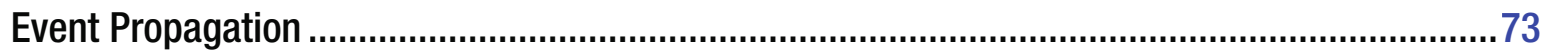

When Should I Worry About Event Propagation? ..................................................................................... 76

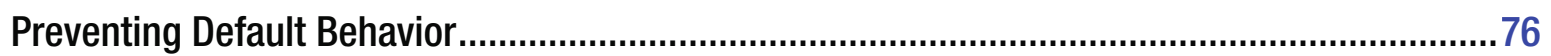

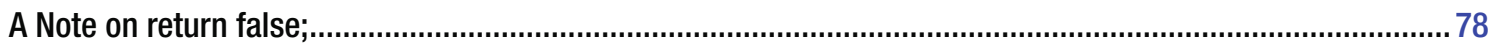

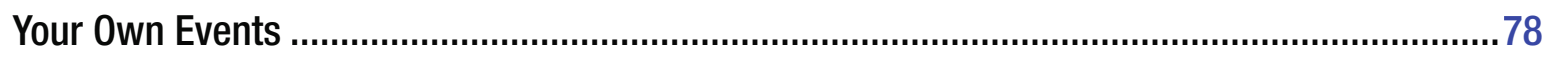

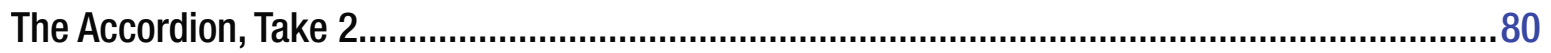

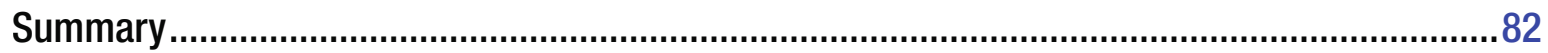

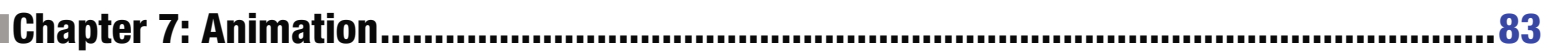

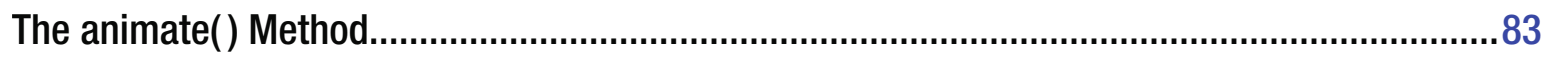

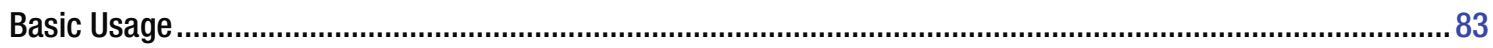

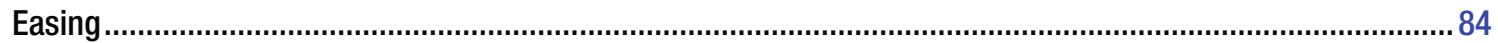

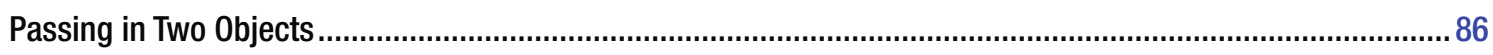

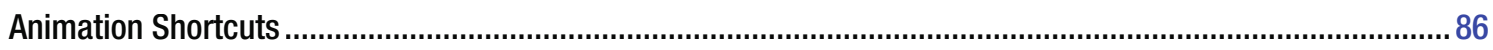

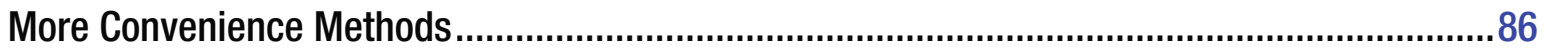

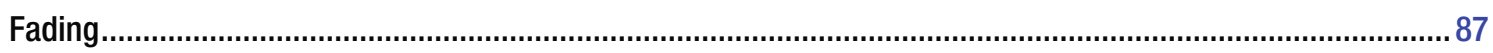

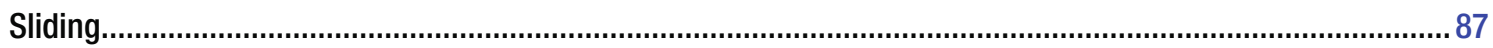

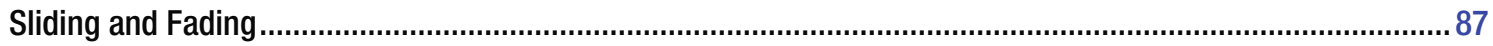

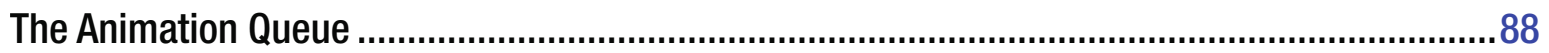

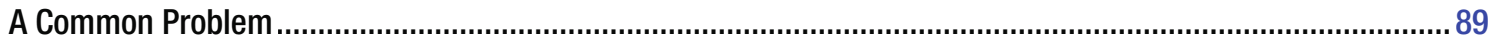

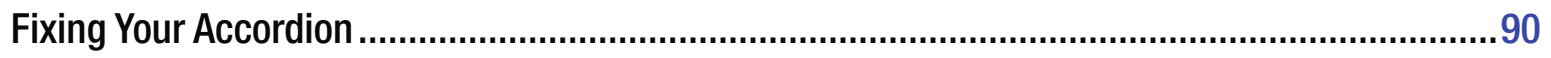

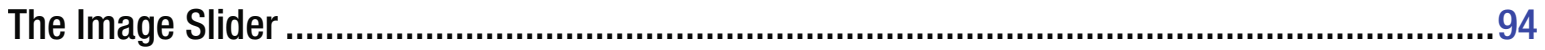

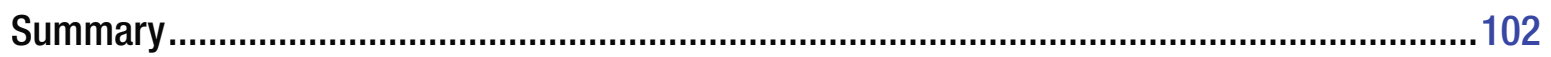

Chapter 8: Ajax with jQuery......................................................................................103

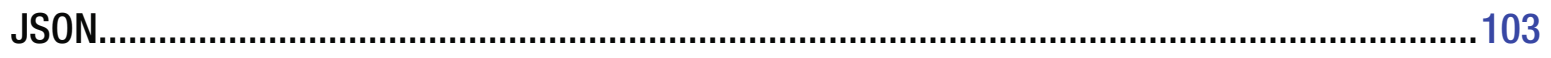

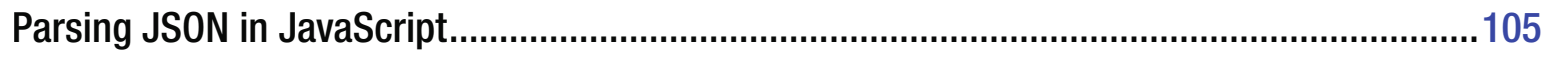


Ajax with jQuery

Setting Up a Local Development Server .......................................................................................... 108

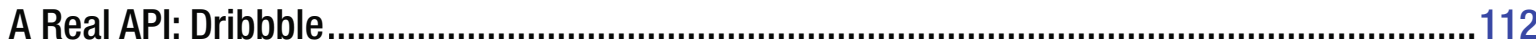

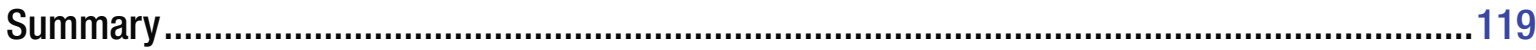

Chapter 9: Writing a jQuery Plug-in.....................................................................121

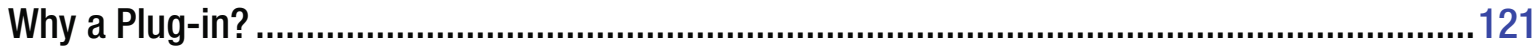

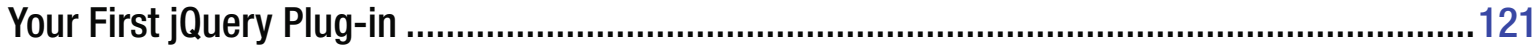

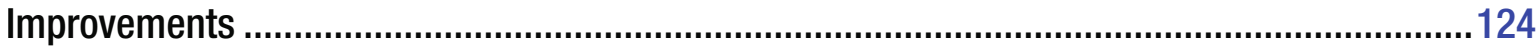

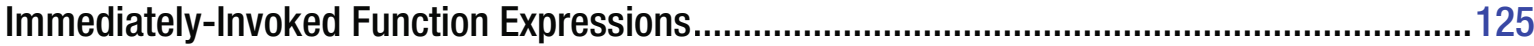

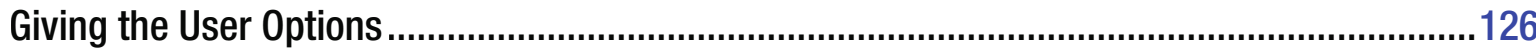

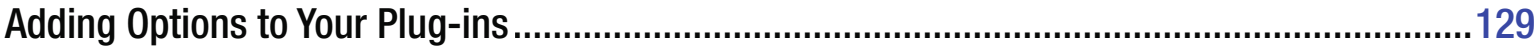

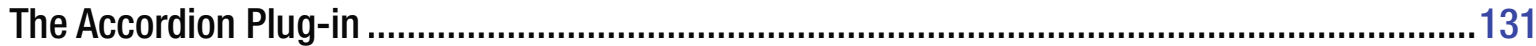

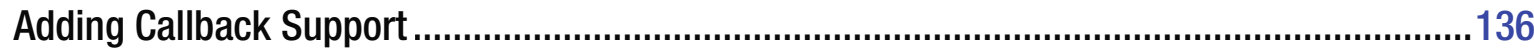

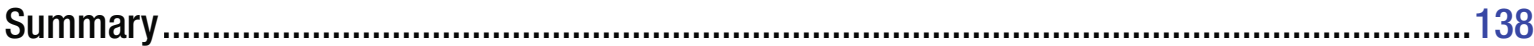

Chapter 10: More jQuery Plug-ins ...............................................................................139

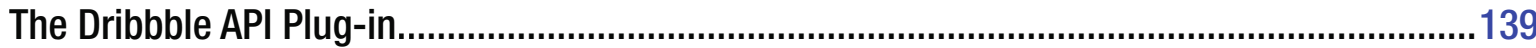

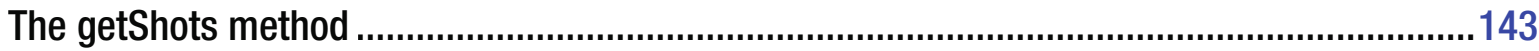

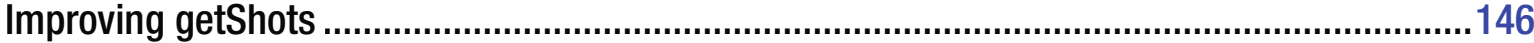

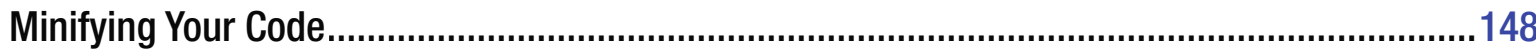

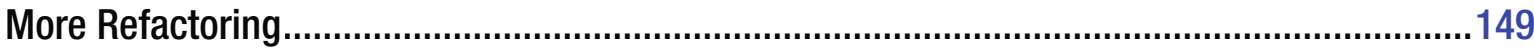

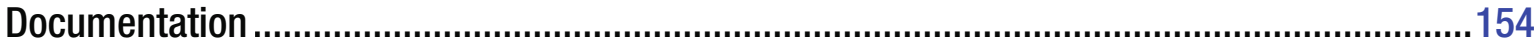

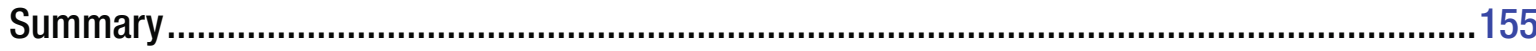

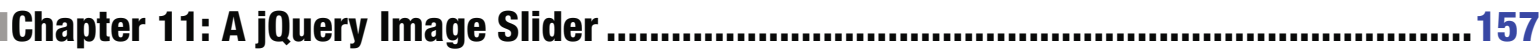

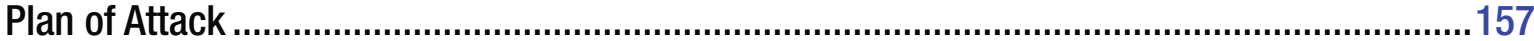

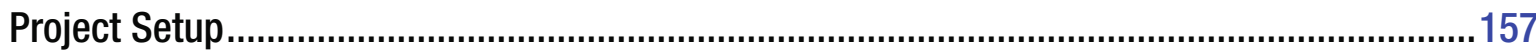

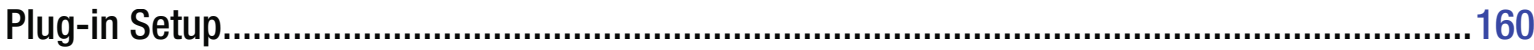

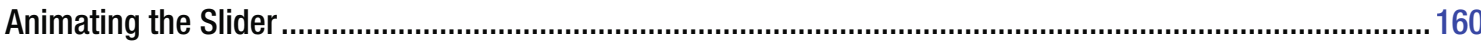




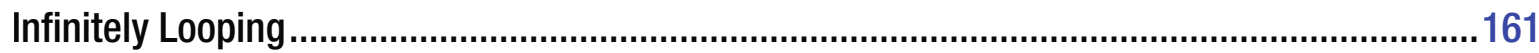

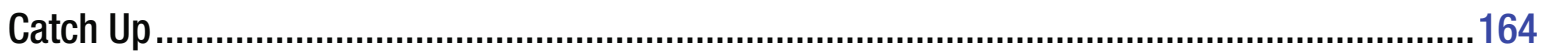

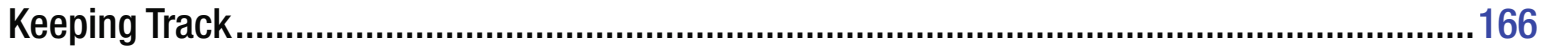

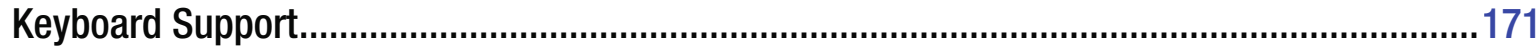

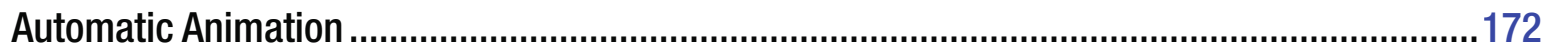

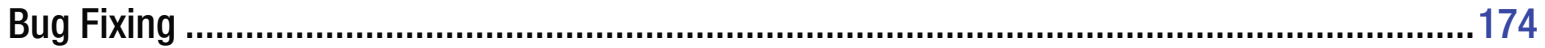

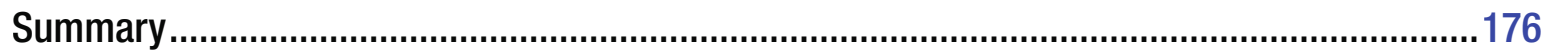

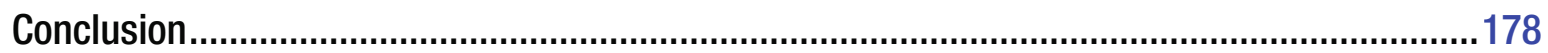

Index 


\section{Foreword}

I'm a Christian, I love my family, I work for appendTo, and I love to learn! I think Jack and I share the common desire to learn.

I first noticed Jack Franklin when he launched the JavaScript Playground web site. I watched as he regularly posted many relevant topics about the front-end development world. I then saw him branch out and experiment with server-side JavaScript-recording and sharing screencasts, speaking at conferences, and now writing this book.

I was honored when he contacted me to write the foreword for his book. jQuery has come a long way since 2006. There have been many books written about it and I'm certain there will be many more to come. The thing I like about Jack is that he is first and foremost a JavaScript scholar. As your read through his book, he takes special care to introduce his readers to proper JavaScript concepts in order to shield them from confusion down the road.

jQuery tends to be an easy library for many developers and designers to learn, but the danger comes when they start to feel friction with the actual JavaScript language, not the jQuery library. Jack appreciates this friction and tries to alleviate that roadblock for his readers.

Jack gives a good overview of the main topics that jQuery covers and provides numerous code examples and snippets for his readers to grasp. I personally find that the technical books I most enjoy reading are ones that have code sprinkled here and there so that I can fully grasp the concepts explained in the prose.

jQuery is a fast-evolving library and new versions come out frequently. As a result, new features are added and others are deprecated from version to version. If you are new to jQuery or need a quick refresher, this book will navigate you toward the appropriate API methods and techniques you'll need to become proficient with the jQuery library. 


\section{About the Author}

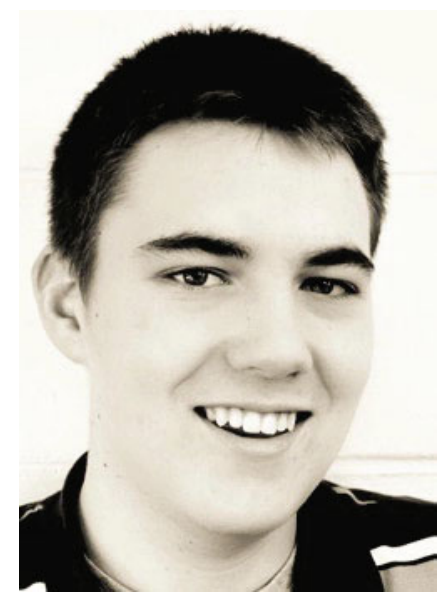

Jack Franklin is a web developer and computer science student from the world heritage city of Bath, in the UK. He started creating web sites in 2005 and has experience in a number of web languages, including HTML, CSS, PHP, Ruby, Python, and others, although his focus is JavaScript. He runs the popular online resource JavaScript Playground (http://javascriptplayground.com) and has released a number of open-source jQuery plug-ins online. 


\section{About the Technical Reviewer}

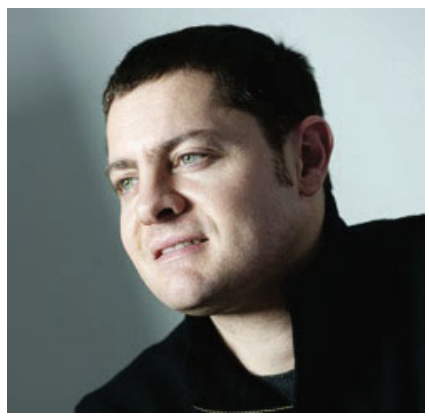

Ian Devlin is an Irish web and app developer who resides in Germany, where he works for pixolith, a web agency in Düsseldorf. He started his working life as a software developer mainly using $\mathrm{C}$, and eventually turned his attention toward web technologies. In addition to writing on his own web site (www. iandevlin. com), Ian writes for HTML5 Doctor and .net magazine, curates at HTML5 Gallery, and has written for Dev.Opera and PC Pro. He has also written a book called HTML5 Multimedia Develop and Design (Peachpit Press, 2011). Outside of all that, he loves European history and taking walks in the countryside. 


\section{Acknowledgments}

I've been fortunate to have so many people help me along my journey to get me to this stage.

The first is Richard Quick, who first got me hooked on the web when I attended my first conference. He went out of his way to make me able to attend and I got home late that evening inspired, knowing it was a path I wanted to venture down.

Then there's all the folks who I got to know when I moved to Bath, who gave me advice, put up with my questions and were always willing to help. People like Dan Dineen, Justin Owen, Jamie Rumbelow, Phil Sturgeon, Julian Cheal everyone at Storm and the guys at Riot. Thanks to Alex Older for giving me my first speaking opportunity at his conference in Bristol too.

Next on the list are my peers at University who put up with me being incredibly unsociable whilst I stayed in coding: Aaron, Grant, Dave, James, Ollie, Cat, Sophie, Helen and loads more.

The opportunity to write a book came about because I started blogging, and a crucial part of that was Toby Howarth, who kindly donated his time to make the site look nice. Thanks to the people who helped spread my articles across the internet and gave me advice: Stuart Robson, Elijah Manor, Anthony Killeen, Dan Sheerman, Addy Osmani, Sindre Sorhus, Rachel Shillcock, Adam Onishi, Michael Heap and Peter Cooper to name but a few.

For the duration of writing this book, I had just started working for Kainos, who were incredibly welcoming and supportive of me. Thanks to everyone there, but in particular to Stuart McKee, Luke McNeice, Will Hamill, Michael Allen, Steven Alexander, James Hughes and Tom Gray.

I was also lucky to meet and work with some other really smart people through work; people like Tim Paul, Roo Reynolds, Tom Loosemore, Ben Howdle and Alice Newton.

Finally, everyone at Apress deserves a medal for putting up with me, and the barrage of questions I sent their way, in particular Mark, Louise and Ian. Along with the rest of the Apress team they've turned my mess of words into this book you're reading. 